\title{
Organic selenium supplementation improves growth parameters, immune and antioxidant status of newly received beef cattle
}

\author{
C.A. Sgoifo Rossi', R. Compiani', G. Baldi'1,4, M. Muraro², J.P. Marden', R. Rossi', G. Pastorelli', \\ C. Corino ${ }^{1}$ and V. Dell'Orto' \\ 1 University of Milan, Department of Health, Animal Science and Food Safety \\ Via Celoria 10, 20133 Milano, Italy \\ ${ }^{2}$ Consorzio Agrario del NORDEST, Via Francia 2, 37135 Verona, Italy \\ ${ }^{3}$ Lesaffre Feed Additives, 137 avenue Gabriel Péri, 59703 Marcq-en-Barœul Cedex, France
}

KEY WORDS: antioxidant status, bovine respiratory disease, immunity, selenium, beef cattle

Received: 16 December 2016

Revised: 13 February 2017

Accepted: $\quad 30$ May 2017

${ }^{4}$ Corresponding author:

e-mail: gianluca.baldi87@gmail.com
ABSTRACT. The effects of dietary supplementation with selenium enriched yeast on growth, immune and antioxidant status were assessed on 228 newly received beef cattle. During the adaptation phase (54 days), the animals were housed in 38 pens (19 pens per treatment) and supplemented with $0.32 \mathrm{mg} \cdot \mathrm{kg}^{-1} \mathrm{DM}$ of Se as sodium selenite (CTR) or selenium enriched yeast $(\mathrm{SeY})$. At days 0,19 and 54 the animals were weighed and blood samples were collected from one healthy animal per pen. During the experimental trial, bovine respiratory disease (BRD) occurrence was monitored. Blood antioxidant status, selenium serum concentration, bovine herpesvirus-1 (BHV-1) antibody titer and serum bactericidal activity were determined. Growth performance was improved $(P<0.05)$ and BRD occurrence was reduced $(P=0.06)$ in SeY group. SeY supplementation increased BHV-1 antibody titre after vaccination, highlighting a positive impact of SeY supplementation on immune system functioning. SeY supplementation improved $(P<0.01)$ selenium serum concentration and positively affected antioxidant status, expressed as Kit Radicaux Libres value, that tended to be higher $(P=0.07)$ in $\mathrm{SeY}$ group, due to Se higher bioavailability. The obtained results suggest that dietary supplementation with organic form of selenium improves growth performance, immune and antioxidant status in newly received beef cattle.

\section{Introduction}

Selenium is an essential trace mineral for livestock. The selenium content in forage reflects the available content in the soil, which varies considerably due to the low soil content in several intensive agricultural areas (Oldfield, 2002). Therefore, selenium supplementation is recommended for livestock, and the requirement for beef cattle is $0.1 \mathrm{mg} \mathrm{Se} / \mathrm{kg} /$ day $(\mathrm{NRC}, 2000)$. Selenium can be provided as inorganic mineral salts, such as sodium selenite $\left(\mathrm{Na}_{2} \mathrm{SeO}_{3}\right)$ or selenate $\left(\mathrm{Na}_{2} \mathrm{SeO}_{4}\right)$, or in organic forms such as $\mathrm{Se}$ enriched yeast (SeY), of which the main form is selenomethionine (SeMet) (Weiss, 2005).

The ability of Se to improve the immune response in farm animals is well documented (Chauhan et al., 2014). Se deficiency has been reported to decrease humoral immune response and neutrophil killing activity in cattle without any clinical signs 
(Hogan et al., 1990). Moreover, Hall et al. (2013) reported that dietary Se supplementation increases antibody titre, neutrophils killing activity and reduces morbidity and mortality in beef cattle. Se improves phagocytosis in white blood cell populations (Hogan et al., 1990). The improvement of immune cell functioning is likely due to the enhanced antioxidant status (Teixeira et al., 2014). The Se role in enhancing the antioxidant status of the organism is mediated by the Se-dependent glutathione peroxidase (GSH-Px) (Battain and Brumaghim, 2009). Usually, reactive oxygen species (ROS) are naturally produced during cellular metabolic processes and are neutralized by the antioxidant system of the organism. In stressful conditions, ROS overproduction negatively affects animal performance, health and wellbeing (Chauhan et al., 2014).

In Italy, beef cattle farming is mainly based on intensive fattening of young cattle imported from other European countries, especially from France (Dell'Orto and Baldi, 2014). Newly received cattle are exposed to several stressors such as weaning, long-distance transport, mixing, feed and water restrictions and new environmental and feed conditions (Sgoifo Rossi et al., 2013). All these factors contribute to pathogen colonization and proliferation, which cause bovine respiratory disease (BRD). However, little is known about the effect of organic or inorganic sources of Se on growth performance, BRD incidence, immune response and antioxidant status of newly received beef cattle.

The objective of this study was to evaluate the effects of dietary supplementation with selenium enriched yeast ( $\mathrm{SeY}$ ) on growth performance, immune parameters and antioxidant status in newly received beef cattle. Due to supporting features of organic Se for immune functioning and the capability to cope against oxidative stress, an improvement in growth performance and health status of highly stressed cattle, due to the higher bioavailability, was expected in contrast to inorganic Se. Considering the high incidence and the detrimental impact of BRD for beef cattle industry, the study evaluated also the effectiveness of a dietary strategy to limit BRD prevalence. A positive result will help to reduce both production cost and antibiotic utilization. To our knowledge no specific data are available about the effectiveness of organic Se supplementation on BRD prevalence, moreover the present study is the first in which the oxidative status in beef cattle was assessed as total antiradical activity.

\section{Material and methods}

\section{Ethical statement}

Procedures involving animals were carried out in accordance with the European Communities Council Directive (2010/63/EU), transposed by the Italian Ministry of Health (DL 26, 4 March 2014).

\section{Animals, management and diet}

Experiment was carried out on a commercial fattening farm located in the northern Italy, during late autumn-winter (2014). Two hundred and twenty eight Limousin $x$ Charolais male cattle imported from France (13 \pm 1 months of age and $375 \pm 30 \mathrm{~kg}$ of live weight) were enrolled and monitored for the adaptation phase (54 days). On arrival, the animals were vaccinated with a commercial inactivated viral vaccine (Cattlemaster $4^{\circledR}$, Pfizer now Zoetis Italia S.r.l., Rome, Italy) containing bovine viral diarrhoea virus (BVDV), bovine herpesvirus-1 (BHV-1), parainfluenza-3 (PI-3V) and bovine respiratory syncytial virus (BRSV). The bullocks were also vaccinated against Mannheimia haemolytica (Pastobov ${ }^{\circledR}$, Merial Italia SpA, Segrate, Milan, Italy). In addition, the animals were treated for the control of both internal and external parasites with ivermectin and clorsulon (Ivomec plus $^{\circledR}$, Merial Italia SpA, Segrate, Milan, Italy). On day 19 a booster vaccination for BHV-1 was administered (Bovilis IBR Marker live ${ }^{\circledR}$, MSD Animal Health S.r.1., Assago, Milan, Italy). BRD risk assessments were conducted (Sgoifo Rossi et al., 2013) and animals were considered as high-risk to develop BRD, therefore they were treated with tulathromycin ${\left(\text { Draxxin }^{\circledR}\right.}^{\circledR}$, Pfizer now Zoetis Italia S.r.l., Rome, Italy). The bullocks were weighed on arrival and conformation was assessed on a 5-point scale (McKiernan, 2007). The animals were blocked by conformation and body weight, and randomly assigned to the two experimental groups. The bullocks were then housed in 38 pens (19 pens per treatment) with 6 animals each. Animals sharing the same pen were homogeneous in terms of conformation and live weight. The pens were equipped with concrete floor covered with straw, with a space allowance of $3.5 \mathrm{~m}^{2} /$ animal in the rest zone, and $0.65 \mathrm{~m} /$ animal at the manger.

The experimental diets were formulated to meet or exceed the requirements for all nutrients (NRC, 2000) and were provided ad libitum for 54 days (Table 1). An average feed intake of $9 \mathrm{~kg} \mathrm{DM} /$ day was expected, based on our previous studies, therefore, the experimental diets were designed to supply $0.32 \mathrm{mg} \cdot \mathrm{kg}^{-1} \mathrm{DM}$ of Se over the natural feed 
Table 1. Composition and chemical analysis of experimental diets

\begin{tabular}{lcc}
\hline \multirow{2}{*}{ Total mixed ration } & \multicolumn{2}{c}{ Dietary treatment ${ }^{1}$} \\
\cline { 2 - 3 } & CTR & $\mathrm{SeY}$ \\
\hline Ingredient, \% on dry matter (DM) basis & & \\
maize silage & 40.0 & 40.0 \\
maize meal & 20.0 & 20.0 \\
beet pulp & 10.0 & 10.0 \\
wheat straw & 10.0 & 10.0 \\
wheat bran & 8.0 & 8.0 \\
sunflower meal & 5.0 & 5.0 \\
soyabean meal & 5.0 & 5.0 \\
calcium carbonate & 0.7 & 0.7 \\
sodium bicarbonate & 0.5 & 0.5 \\
sodium chloride & 0.3 & 0.3 \\
urea & 0.3 & 0.3 \\
vitamin-mineral premix with sodium & 0.2 & - \\
$\quad$ selenite & & \\
vitamin-mineral premix with selenium & - & 0.2 \\
$\quad$ enriched yeast & \\
Nutritional value & & \\
metabolizable energy, MJ · kg ${ }^{-1}$ DM ${ }^{3}$ & 9.95 & 9.95 \\
crude protein, \% DM & 12.7 & 12.4 \\
neutral detergent fibre, \% DM & 39.7 & 40.5 \\
acid detergent fibre, \% DM & 22.1 & 22.7 \\
starch, \% DM & 28.8 & 29.4 \\
ether extract, \% DM & 2.52 & 2.49 \\
ash, \% DM & 7.23 & 7.20 \\
Ca, \% DM & 0.83 & 0.82 \\
P, \% DM & 0.41 & 0.42 \\
Se, mg · kg-1 DM & 0.44 & 0.43 \\
\hline
\end{tabular}

${ }^{1} \mathrm{CTR}$ - with sodium selenite addition (control), SeY - with selenium enriched yeast addition; ${ }^{2}$ mineral and vitamin concentration per $\mathrm{kg}$ of mineral and vitamin mixes: IU: vit. A 4000 000, vit. $D_{3} 400$ 000; mg: vit. E 25 000, vit. $B_{1} 1500$, biotin 1500 , niacin 100000 , Co 150, Mn 10 000, Se 160, Zn 25 000, Fe 8 500, I 500; ; estimated from the reference values according to NRC (2000)

content, in order to supply $3 \mathrm{mg} /$ head/day, according to the results of previous study (Cozzi et al., 2011). The overall dietary Se was higher than $0.32 \mathrm{mg} \cdot \mathrm{kg}^{-1}$ due to the natural feed Se content. The control group (CTR) received sodium selenite while the treated group was fed the same dosage of Se in organic form, as selenium enriched yeast (SeY). This product was produced by a specific strain of Saccharomyces cerevisiae CNCM-I3399 (Selsaf $\AA$, EC No. 3b8.12, Lesaffre Italia, Trecasali, Parma, Italy) containing a minimum of $2 \mathrm{~g}$ of Se $/ \mathrm{kg}$, in which inorganic Se accounted for less than $<1 \%$ of the total Se. Organic Secompounds were represented principally by selenomethionine $(62.7 \%)$ and selenocysteine $(2 \%$ to $4 \%$ of total Se), while the remaining organic Se-compounds were not specified (EFSA, 2009).

Se supplements were included in two different trace mineral and vitamin mixes, designed to provide the same amount of micronutrients. The diet in total mixed ratio (TMR) form was prepared and delivered daily in the morning and offered ad libitum (Table 1).

\section{Data collection and sampling}

Before the morning feeding, on days 0 (arrival), 19 (at the booster vaccination treatment) and 54 the cattle were individually weighed and the average daily gain $(A D G)$ was calculated. Before further feed administration, the feed intake was recorded daily by weighing the feed distributed and the residue in the manger $24 \mathrm{~h}$ later. Pen feed conversion ratio (FCR) was calculated. Animals were inspected twice a day by the farm veterinary staff and were considered affected by BRD if the rectal temperature was $\geq 40.0^{\circ} \mathrm{C}$ and if both depression score and respiratory character score differed from the normal health status (score 0 of Baggott et al., 2011). The animals diagnosed as affected by BRD were treated with two doses of florfenicol $\left(1 \mathrm{ml} / 15 \mathrm{~kg}\right.$ of live weight - Nuflor $^{\circledR}$, MSD Animal Health S.r.l., Segrate, Milan, Italy) $48 \mathrm{~h}$ apart.

Blood samples were collected before the morning feeding from all the animals on days 0,19 and 54. Blood samples were collected by jugular venipuncture into $10 \mathrm{ml}$ EDTA tubes and $10 \mathrm{ml} \mathrm{no}$ additive tubes (Venoject ${ }^{\circledR}$, Terumo Europe N.V., Leuven, Belgium) and immediately placed on ice. Two tubes were collected for each cattle, one was used for Kit Radicaux Libres (KRL) test and the other for serum extraction. Serum samples were obtained by centri-fugation at $3000 \mathrm{~g}$ for $10 \mathrm{~min}$ at $4{ }^{\circ} \mathrm{C}$ and stored at $-20^{\circ} \mathrm{C}$. In order to prevent a possible confounding effect of BRD on blood parameters, at the end of the experimental period serum was analysed only from 1 animal per pen $(n=38)$ randomly chosen within those not affect by BRD. KRL test was performed only on eligible cattle (that have never experienced BRD since the beginning of the trial to the bleeding). Only data related to the cattle selected for serum analysis were used in the present paper.

\section{Analysis of experimental diets}

Samples of the experimental diet (100 g/each) were collected every two weeks, pooled and analysed for dry matter, crude protein, ether extract, starch and ash, according to the AOAC (1990) methods. Neutral detergent fibre was determined according to Van Soest et al. (1991). The net energy content of the diet, measured in Unite Fourragère Viande (UFV), was calculated using the reference values for all feed ingredients reported by NRC (2000). Feed selenium concentration was determined by a commercial laboratory using fluoro-metric methods according to AOAC (1990). 


\section{Serum analysis}

Serum Se was determined by an external accredited laboratory using inductively coupled plasma mass spectrometry (ICPMS; Agilent 7500 CX series, Agilent Technologies, Santa Clara, CA, USA), with a procedure according to UNI CEI EN ISO/IEC 17025:2005 standard, following the method reported by van de Wiel (2003). The BHV-1 serum neutralization test was performed according to OIE (2012). Neutralizing antibody titre was measured against the homologous vaccine virus. Antibodies were titrated by the constant virus-varying serum dilution from $1 / 2$ onwards. The data of the neutralizing antibody titres were transformed, $\log (1 / \mathrm{x})$, where $\mathrm{x}$ was the serum dilution. Serum bactericidal activity was performed according to Amadori et al. (1997).

\section{Blood analysis}

Total antiradical activity of whole blood and red blood cells (RBC) was evaluated using a KRL biological test (Laboratoires Spiral, Couternon, France). Analyses were performed within $24 \mathrm{~h}$ of sample collection. The principle of the KRL test is to submit whole blood and RBC to thermo-controlled free radical aggression, in order to mobilize all families of any free radical scavengers present in the blood to neutralize the oxidation processes (Girodon et al., 1997; Stocker et al., 2003). All chemical and enzymatic antioxidant systems were triggered to protect cells integrity until lysis. Whole blood and RBC samples were submitted in an isotonic saline solution to organic free radicals produced at $37{ }^{\circ} \mathrm{C}$ under air atmosphere from the thermal decomposition of 2,2'-azobis (2-amidinopropane) dihydrochloride (AAPH) solution (Kirial International, Dijon, France). Haemolysis was recorded using a 96-well microplate reader by measuring the optical density decay at $450 \mathrm{~nm}$. For each well, absorbance measurements were performed 75 times, one every $150 \mathrm{~s}$. Results were expressed as KRL value, which is the time required to reach $50 \%$ of maximal haemolysis (half-haemolysis time $-\mathrm{HT}_{50}$ - in minutes), which refers to the whole blood resistance to free-radical attack. Intra- and inter-assay coefficients of variation of the KRL test were $2.5 \%$ and $4 \%$, respectively.

\section{Statistical analysis}

Statistical analyses were performed using SAS 9.3 (2010; SAS Institute Inc., Cary, NC, USA). The value of each pen was considered as the experimental unit for growth performance parameters. A twoway analysis of variance (ANOVA) was performed considering the fixed effect of treatment, time and their interactions. The effect of Se source on ADG was tested also within health status. Single animal was considered as the experimental unit. A three-way ANOVA was performed considered the fixed effects of dietary treatment, time, health status and their interactions. For blood and serum analyses, animal was considered as the experimental unit. A repeated measure ANOVA was performed with the fixed effect of treatment, time and their interaction. Values recorded on day 0 were used as the covariate. The effect of dietary treatment on BRD incidence was evaluated using a chi-square test. The significance level was set as $P \leq 0.05$. Data are presented as least squared means and pooled standard error of the means (SEM).

\section{Results}

\section{Rearing performance and BRD incidence}

The final live weight did not differ between experimental groups $(P>0.05$; Table 2$)$. The ADG was higher $(P=0.01)$ in the SeY group than CTR group in the second phase of the trial and in

Table 2. Effect of selenium source on growth, feed consumption and bovine respiratory disease frequency during adaptation phase in newly received beef cattle

\begin{tabular}{|c|c|c|c|c|c|c|}
\hline \multirow{2}{*}{ Indices } & \multicolumn{2}{|c|}{ Dietary treatment ${ }^{1}$} & \multirow{2}{*}{$\begin{array}{l}\text { Pooled } \\
\text { SEM }\end{array}$} & \multicolumn{3}{|l|}{$P$-value } \\
\hline & CTR & $\mathrm{SeY}$ & & treatment, $\mathrm{t}$ & day, d & $t \times d$ \\
\hline \multicolumn{7}{|c|}{ Live weight, $\mathrm{kg}$} \\
\hline day 0 & 382 & 368 & & & & \\
\hline 19 & 402 & 390 & & & & \\
\hline 54 & 453 & 448 & 49.82 & 0.30 & $<0.001$ & 0.37 \\
\hline \multicolumn{7}{|c|}{ Average daily gain, $\mathrm{kg} \cdot \mathrm{d}^{-1}$} \\
\hline days $0-19$ & 1.08 & 1.19 & & & & \\
\hline $19-54$ & $1.46^{\mathrm{A}}$ & $1.65^{\mathrm{B}}$ & & & & \\
\hline $0-54$ & $1.32^{\mathrm{A}}$ & $1.45^{\mathrm{B}}$ & 0.04 & 0.01 & $<0.001$ & 0.01 \\
\hline \multicolumn{7}{|c|}{ Dry matter intake, $\mathrm{kg} \cdot \mathrm{d}^{-1}$} \\
\hline days $0-19$ & $7.52^{\mathrm{a}}$ & $8.35^{\mathrm{b}}$ & & & & \\
\hline $19-54$ & 9.66 & 9.88 & & & & \\
\hline $0-54$ & $8.91^{\mathrm{a}}$ & $9.34^{b}$ & 0.57 & 0.01 & $<0.001$ & 0.05 \\
\hline \multicolumn{7}{|c|}{ Feed conversion ratio } \\
\hline days $0-19$ & 6.96 & 7.02 & & & & \\
\hline $19-54$ & $6.62^{\mathrm{a}}$ & $6.13^{b}$ & & & & \\
\hline $0-54$ & $6.75^{\mathrm{a}}$ & $6.44^{\mathrm{b}}$ & 0.53 & 0.03 & $<0.001$ & 0.04 \\
\hline
\end{tabular}

Incidence of bovine respiratory disease, $\%$

\begin{tabular}{rrrrrrr} 
days $0-19$ & 29.82 & 24.56 & - & 0.06 & - & - \\
$19-54$ & 12.28 & 9.65 & - & 0.17 & - & - \\
$0-54$ & 42.11 & 34.21 & - & 0.06 & - & - \\
\hline
\end{tabular}

${ }^{1}$ CTR - with sodium selenite addition (control), SeY - with selenium enriched yeast addition; values are given as least square means; pooled SEM - pooled standard error of the mean; ${ }^{a b}$ and ${ }^{A B}$ - means within a row with different superscripts are significantly different at $P \leq 0.05$ or $P \leq 0.01$, respectively; live weight, average daily gain, dry matter intake, feed conversion ratio - average values of pens $(n=19$ per group); incidence of bovine respiratory disease - average values of animals ( $n=114$ per group) 
Table 3. Effect of selenium source (sodium selenite, CTR; selenomethionine from yeast, SeY) within health status (healthy or with bovine respiratory disease (BRD)) on average daily gain during the adaptation phase in newly received beef cattle, $\mathrm{kg} \cdot \mathrm{d}^{-1}$

\begin{tabular}{|c|c|c|c|c|c|c|c|c|c|}
\hline \multirow{3}{*}{ Indices } & \multicolumn{4}{|c|}{ Health status } & \multirow{3}{*}{$\begin{array}{l}\text { Pooled } \\
\text { SEM }\end{array}$} & \multirow{2}{*}{\multicolumn{4}{|c|}{$P$-value }} \\
\hline & \multicolumn{2}{|c|}{ healthy } & \multicolumn{2}{|l|}{ BRD } & & & & & \\
\hline & CTR & $\mathrm{SeY}$ & CTR & $\mathrm{SeY}$ & & treatment, $\mathrm{t}$ & health status, $\mathrm{h}$ & $\mathrm{t} \times \mathrm{h}$ & $\mathrm{d} \times \mathrm{h} \times \mathrm{t}$ \\
\hline No. of animals & 66 & 75 & 48 & 39 & & & & & \\
\hline \multicolumn{10}{|c|}{ Average daily gain, $\mathrm{kg} \cdot \mathrm{d}^{-1}$} \\
\hline days $0-19$ & $1.31^{\mathrm{a}}$ & $1.39^{a}$ & $0.75^{b}$ & $0.75^{b}$ & 0.03 & \multirow{3}{*}{0.03} & \multirow{3}{*}{$<0.001$} & \multirow{3}{*}{0.83} & \multirow{3}{*}{$<0.001$} \\
\hline $19-54$ & $1.56^{b}$ & $1.73^{a}$ & $1.31^{\mathrm{c}}$ & $1.51^{b}$ & 0.03 & & & & \\
\hline $0-54$ & $1.44^{\mathrm{b}}$ & $1.56^{\mathrm{a}}$ & $1.03^{c}$ & $1.26^{c}$ & 0.03 & & & & \\
\hline
\end{tabular}

values are given as least square means; pooled SEM - pooled standard error of the mean; ${ }^{\text {a-d }}$ - means within a row with different superscripts are significantly different at $P<0.05$

the overall experimental period (days 19-54; days $0-54)$. SeY supplemented animals also showed a higher DMI $(P=0.04)$ and a better FCR $(P=0.03)$ than the CTR group. A time effect $(P<0.001)$ was observed for all the variables considered. During the experimental period, no other health problems were recorded. The BRD incidence tended to be lower $(P=0.06)$ in animals fed SeY than CTR. The BRD significantly reduced growth performances $(P<0.001)$ throughout the experiment (Table 3$)$. In cattle affected by BRD, dietary SeY supplementation improved $(P<0.05)$ ADG during the second phase of the trial. The overall ADG in BRD affected animals was numerically higher in the SeY group. Within healthy animals, those fed $\mathrm{SeY}$ showed a better ADG $(P<0.05)$ in the second phase of the trial and throughout the experimental period (days 19-54 and 0-54, respectively).

\section{Serum analyses}

Dietary treatment with $\mathrm{SeY}$ and sampling time positively affected the serum Se concentration $(P<0.01)$ (Table 4). An interaction between dietary treatment and time was also observed $(P=0.02)$. The neutralizing antibodies against BHV-1 were higher $(P<0.01)$ in the SeY group than in CTR animals, which showed, therefore, a better immune reaction. Serum BHV-1 antibody titre increased after booster vaccination $(P<0.01)$ as expected. Dietary supplementation with different Se sources did not affect $(P>0.05)$ serum bactericidal activity.

\section{Antioxidant status}

The antioxidant status tended to be higher $(P=0.07)$ in animals fed SeY than CTR (Figure 1a). The KRL value of RBC did not differ $(P=0.31)$ between the two groups (Figure 1b). For both whole blood and RBC, a time effect was also evident $(P<0.01)$, with an increase in half-haemolysis time.
Table 4. Effect of selenium source on serum Se concentration, neutralizing antibody after vaccination and bactericidal activity during adaptation phase in healthy newly received beef cattle

\begin{tabular}{|c|c|c|c|c|c|c|}
\hline \multirow{2}{*}{ Indices } & \multicolumn{2}{|c|}{$\begin{array}{l}\text { Dietary } \\
\text { treatment }{ }^{1}\end{array}$} & \multirow{2}{*}{$\begin{array}{l}\text { Pooled } \\
\text { SEM }\end{array}$} & \multicolumn{3}{|l|}{$P$-value } \\
\hline & CTR & $\mathrm{SeY}$ & & treatment, $\mathrm{t}$ & day, d & $t \times d$ \\
\hline Serum Se, $\mu \mathrm{g} \cdot \mathrm{I}^{-1}$ & & & 1.38 & $<0.01$ & $<0.01$ & 0.02 \\
\hline day 19 & $106.11^{a}$ & $116.13^{b}$ & & & & \\
\hline 54 & $108.64^{a}$ & $118.62^{b}$ & & & & \\
\hline $\begin{array}{l}\text { Neutralizing } \\
\text { antibody, } \log (1 / x)\end{array}$ & & & 0.05 & $<0.01$ & $<0.01$ & 0.05 \\
\hline day 19 & $0.54^{\mathrm{a}}$ & $0.78^{b}$ & & & & \\
\hline 54 & $1.10^{\mathrm{A}}$ & $1.42^{\mathrm{B}}$ & & & & \\
\hline $\begin{array}{l}\text { Serum bactericidal } \\
\text { activity, } \%\end{array}$ & & & 7.82 & 0.22 & $<0.01$ & 0.76 \\
\hline day 19 & 91.47 & 92.60 & & & & \\
\hline 54 & 92.38 & 93.43 & & & & \\
\hline
\end{tabular}

${ }^{1}$ CTR - with sodium selenite addition (control), SeY - with selenium enriched yeast addition; values are given as least square means; pooled SEM - pooled standard error of the mean; ${ }^{a b}$ and ${ }^{A B}$ - means within a row with different superscripts are significantly different at $P \leq 0.05$ or $P \leq 0.01$, respectively; $n=19$ (one healthy beef cattle from each pen)

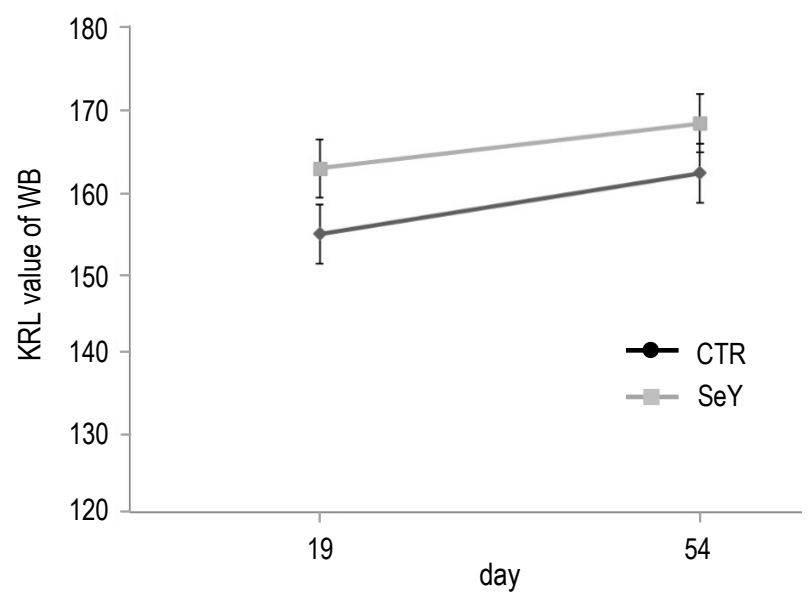

Figure 1a. Effect of dietary selenium source (sodium selenite, CTR; selenium enriched yeast, SeY) on Kit Radicaux Libres (KRL) value of whole blood (WB) of newly received beef cattle during adaptation phase. Values at day 0 were used as covariate; values are given as least square means \pm standard error of the mean 


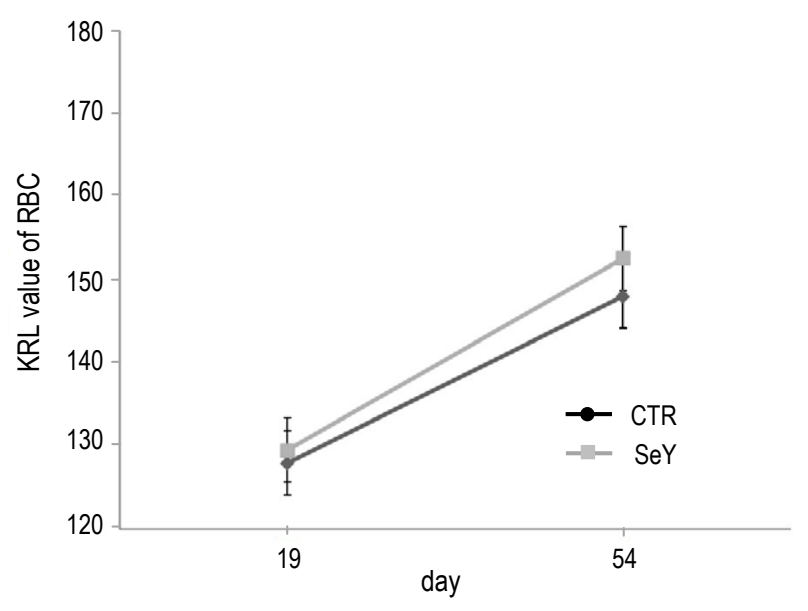

Figure 1b. Effect of dietary selenium source (sodium selenite, CTR; selenium enriched yeast, $\mathrm{SeY}$ ) on Kit Radicaux Libres (KRL) value of red blood cells (RBC) of newly received beef cattle during adaptation phase. Values at day 0 were used as covariate; values are given as least square means \pm standard error of the mean

\section{Discussion}

The present study confirms the detrimental impact of bovine respiratory disease (BRD) on cattle performance. Respiratory disease is, indeed, the most impacting disease in the beef industry and is a multifactorial syndrome, involving infections, the environment and the stress and the immunity of the animal (Panciera and Confer, 2010). BRD is sustained by viruses as bovine herpesvirus 1 , BVDV (bovine viral diarrhoea), PI3V (parainfluenza type-3 virus), BRSV (bovine respiratory syncytial virus) and BAV-3 (bovine adenovirus 3), bacteria, such as Pasteurella multocida and Mannheimia spp. and mycoplasma (e.g., Mycoplasma bovis) (Radostits et al., 2007). In BRD affected cattle the observed impairment of growth performance can be explained by the induced anorexia promoted by proinflammatory cytokines released during infection (Buhman et al., 2000) coupled with the rising of energy and protein requirements to support immune reactions and acute phase protein synthesis (Krehbiel et al., 2012).

The Se concentration found in both groups fell within the optimal range of $85-300 \mu \mathrm{g} \cdot 1^{-1}$ of serum Se proposed by Puls et al. (1994), and was similar to the values reported by Nicholson et al. (1991) and Richards et al. (2011) in newly received beef cattle. The present data confirm the higher bioavailability of organic Se supplementation compared to the inorganic form, as reviewed by Spears (2003) and agree with the findings of Nicholson et al. (1991) and Cozzi et al. (2011) in beef cattle.
As indicated by Weiss (2005), dietary selenomethionine (SeMet), the prevalent form in the SeY used in our study, is incorporated in bacterial protein, which thus becomes part of digestible protein, while the remaining portion is efficiently absorbed at the gut level through a Met carrier. On the other hand, most of the selenite is converted into lowabsorbable compounds or used by microbes to synthesize seleno-amino acids. The portion of selenite that escapes the rumen is absorbed via passive transfer. After absorption, SeMet can be incorporated into proteins to replace the Met, or catabolized and the Se utilized to synthesize selenocysteine. However, selenite is reduced to selenide and the amount not immediately converted into selenocysteine is methylated and excreted.

Feeding a supra-nutritional dose of SeY compared to no supplementation to dairy cows, beef cattle, lambs and calves, Juniper et al. (2008a) found that 40 to $75 \%$ of blood selenium in the supplemented group was in the SeMet form, while no SeMet was found in the control group.

The improvement in BHV-1 antibody production, in agreement with the findings of Nicholson et al. (1991), can reflect a higher lymphocyte B activity due to a higher GSH-Px activity thanks to the higher bioavailability of organic Se. As reported by Arthur et al. (2003) Se improves vitality and activity of immune cells including lymphocyte B.

Serum bactericidal activity is a marker of nonspecific immunity and is linked to the complement system and natural antibodies to inhibit the activity of some bacterial strains characterized by low pathogenicity. In normal conditions, serum bactericidal activity has to be higher than $90 \%$ (Amadori et al., 2002). Due to the stressors associated with transport, animals showed a lower serum bactericidal activity than the optimal threshold on arrival, while it increased during the adaptation phase. This increase underlines a recovery after marketing stress, according to the findings of Compiani et al. (2013) in animals affected by similar stressful conditions.

The KRL test evaluates the antioxidant status of an organism by testing the antioxidant defences in both plasma and RBC (Prost, 1992). This test has several applications both in in vivo and in vitro studies. In humans, it has been used to study the effectiveness of antioxidant vitamins and pharmaceutical treatments (Lesgards et al., 2005). In in vitro studies the antioxidant potential of synthetic and natural antioxidant has been evaluated (Rossi et al., 2009). In several studies on animals, the antioxidant status has also been tested using the KRL test 
(Rossi et al., 2013). This method is effective in evaluating the antioxidant status of animals in relation to dietary antioxidant supplementation and induced oxidative stress (Rossi et al., 2013; Di Giancamillo et al., 2015). We found that the blood total antiradicalic activity is enhanced by SeY supplementation. This data agrees with the experiments of Juniper et al. (2008a) in which supplemented ruminants showed even higher blood glutathione peroxidase and Juniper et al. (2008b) where a higher glutathione peroxidase activity in beef cattle fed organic Se compared to those fed sodium selenite was reported. Cozzi et al. (2011) also found a positive relationship between blood Se content and glutathione peroxidase activity.

The mechanism beyond this finding is explained in the review of Hefnawy and Tórtora-Pèrez (2010). GSH-Px is a selenoprotein that contains SeMet at its active site and GSH-Px synthesis is affected by Se availability. Se allocation into the organs is hierarchized as follows: brain, spinal cord, pituitary gland, thyroid, ovaries and adrenal gland. Therefore, phospholipid hydroperoxidase (PHGSH-Px) has the priority over the plasmatic and cellular GSH-Px. Indeed, in case of Se deficiency it was shown that brain Se was just $60 \%$ of the normal value, while liver, blood and muscle Se were below $1 \%$ of the normality. Based on these data it is evident that increasing the available Se through the diet will lead to a rising of GSH-Px and, therefore, the antioxidant potential.

A lack of effect of SeY supplementation on RBC antiradical capacity was expected. In fact, the analysis on whole blood measures intracellular and extracellular defences, whereas RBC data concerns the intracellular defence status. The RBC mean life in cattle is around 130-150 days (Adili and Melizi, 2014). The $\mathrm{SeY}$ was supplemented only for 54 days, which is too short to highlight an effect on this parameter. In fact, the $\mathrm{RBC}$ antiradicalic activity value is important in the interpretation of the antioxidant status of an organism in a medium/long period. On the other hand, whole blood value provides information on the physiological status and could be especially useful for the evaluation of dietary integration.

An increased ability to cope against oxidative stress, as highlighted by the KRL test on whole blood, and an improvement in the immune function may have been the means by which organic Se supplement reduced BRD occurrence in comparison to the inorganic one.

As previously reported for serum bactericidal activity, the increasing antiradical activity during the experimental period underlines a progressive recovery after market stress and the adaptation to the new environment.

\section{Conclusions}

The supplementation of selenium from selenium enriched yeast instead of sodium selenite improved growth performance, immune function and antioxidant status in newly received beef cattle. The tested strategy, therefore, seemed to be helpful to counteract the negative effects of the market and transport stress which typically affect newly received beef cattle. However, further studies are necessary to better explain the mechanism of action of organic selenium and to confirm the beneficial effects of selenium yeast supplementation during the adaptation period of newly received beef cattle.

\section{References}

Adili N., Melizi M., 2014. Preliminary study of the influence of red blood cells morphometry on the species determinism of domestic animals. Vet. World 7, 219-223, https://doi.org/10.14202/ vetworld.2014.219-223

Amadori M., Archetti I.L., 2002. Determination of serum bactericide with micromethod test (in Italian). In: M. Amadori, I.L. Archetti (Editors). The Evaluation of Wellnes in Bovine Species (in Italian). Fondazione Iniziative Zooprofilattiche e Zootecniche. Brescia (Italy), pp. 61-64

Amadori M., Archetti I.L., Frasnelli M., Bagni M., Olzi E., Caronna G., Lanteri M., 1997. An immunological approach to the evaluation of welfare in Holstein Frisian cattle. J. Vet. Med. Ser. B 44, 321-327, https://doi.org/10.1111/j.1439-0450.1997.tb00982.x

AOAC, 1990. Official Methods of Analysis of the Association of Official Analytical Chemists. $15^{\text {th }}$ Edition. Arlington, VA (USA)

Arthur J.R., McKenzie R.C., Beckett G.J., 2003. Selenium in the immune system. J. Nutr. 113, 1457S-1459S

Baggott D., Casartelli A., Fraisse F., Manavella C., Marteau R., Rehbein S., Wiedemann M., Yoon S., 2011. Demonstration of the metaphylactic use of gamithromycin against bacterial pathogens associated with bovine respiratory disease in a multicentre farm trial. Vet. Rec. 168, 241-245, https://doi. org/10.1136/vr.c6776

Battin E.E., Brumaghim J.L., 2009. Antioxidant activity of sulfur and selenium: a review of reactive oxygen species scavenging, glutathione peroxidase, and metal-binding antioxidant mechanisms. Cell Biochem. Biophys. 55, 1-23, https://doi. org/10.1007/s12013-009-9054-7

Buhman M.J., Perino L.J., Galyean M.L., Wittum T.E., Montgomery T.H., Swingle R.S., 2000. Association between changes in eating and drinking behaviours and respiratory tract disease in newly arrived calves at a feedlot. Am. J. Vet. Res. 61, 1163-1168, https://doi.org/10.2460/ajvr.2000.61.1163

Chauhan S.S., Celi P., Ponnampalam E.P., Leury B.J., Liu F., Dunshea F.R., 2014. Antioxidant dynamics in the live animal and implications for ruminant health and product (meat/milk) quality: role of vitamin E and selenium. Anim. Prod. Sci. 54, 1525-1536, https://doi.org/10.1071/AN14334 
Compiani R., Sgoifo Rossi C.A., Pizzi A., Dell'Orto V., 2013. Administration of essential oils of cinnamaldehyde, eugenol, and capsicum to beef cattle: effects on health status and growth performances. In: C. Boiti, A. Ferlazzo, A. Gaiti, A. Pugliese (Ediotrs). Trends in Veterinary Sciences - Current Aspects in Veterinary Morphophysiology, Biochemistry, Animal Production, Food Hygiene and Clinical Sciences. Springer-Verlag $\mathrm{GmbH}$, Berlin (Germany), pp. 177-180, https://doi. org/10.1007/978-3-642-36488-4_32

Cozzi G., Prevedello P., Stefani A.L., Piron A., Contiero B., Lante A., Gottardo F., Chevaux E., 2011. Effect of dietary supplementation with different sources of selenium on growth response, selenium blood levels and meat quality of intensively finished Charolais young bulls. Animal 5, 1531-1538, https://doi. org/10.1017/S1751731111000711

Dell'Orto V., Baldi G., 2014. Overview of beef cattle production in Italy. In: Proceedings of the International Workshop Animal Nutrition, Natural Feeding Sources and Environmental Sustainability. Arzachena, Sardinia (Italy), pp. 24-30

Di Giancamillo A., Rossi R., Pastorelli G., Deponti D., Carollo V., Casamassima D., Domeneghini C., Corino C., 2015. The effects of dietary verbascoside on blood and liver oxidative stress status induced by a high n-6 polyunsaturated fatty acids diet in piglets. J. Anim. Sci. 93, 2849-2859, https://doi.org/10.2527/ jas.2014-8607

EFSA, 2009. Scientific Opinion of the Panel on Additives and Products or Substances used in Animal Feed (FEEDAP) on a request from the European Commission on the safety and efficacy of SELSAF (Selenium enriched yeast from Saccharomyces cerevisiae CNCM I-3399) as feed additive for all species. EFSA J. 7, 992, https://onlinelibrary.wiley.com/doi/10.2903/j. efsa.2009.992/full

Girodon F., Blache D., Monget A.L., Lombart M., Brunet-Lecompte P., Arnaud J., Richard M.J., Galan P., 1997. Effect of two-year supplementation with low doses antioxidant vitamins and/or minerals in elderly subjects on levels of nutrients and antioxidant defense parameters. J. Am. Coll. Nutr. 16, 357-365, https://doi.org/10.1080/07315724.1997.10718698

Hall J.A., Gerd B., Vorachek W.R., Hugejiletu, Gorman M.E., Mosher W.D., Pirelli G.J., 2013. Effects of feeding seleniumenriched alfalfa hay on immunity and health of weaned beef calves. Biol. Trace Elem. Res. 156, 96-110, https://doi. org/10.1007/s12011-013-9843-0

Hefnawy A.E.G., Tórtora-Pèrez J.L., 2010. The importance of selenium and the effects of its deficiency in animal health. Small Rumin. Res. 89, 185-192, https://doi.org/10.1016/j.smallrumres.2009.12.042

Hogan J.S., Smith K.L., Weiss W.P., Todhunter D.A., Schockey W.L., 1990. Relationships among vitamin $E$, selenium, and bovine blood neutrophils. J. Dairy Sci. 73, 2372-2378, https://doi. org/10.3168/jds.S0022-0302(90)78920-5

Juniper D.T., Philips R.H., Givens I., Jones A.K., Green C., Bertin G., 2008a. Tollerance of ruminant animals to high dose in-feed administration of a selenium-enriched yeast. J. Anim. Sci. 86, 197-204, https://doi.org/10.2527/jas.2006-773

Juniper D.T., Phipps R.H., Ramos-Morales E., Bertin G., 2008b. Effect of dietary supplementation with selenium-enriched yeast or sodium selenite on selenium tissue distribution and meat quality in beef cattle. J. Anim. Sci. 86, 3100-3109, https://doi. org/10.2527/jas.2007-0595

Krehbiel C.R., Terrill S.J., Mills R.L., Gifford C.A., Step D.L., Richards C.J., Burciaga Robles L.O., 2012. Inflammation and nutrient metabolism in ruminants. In: Proceedings of $23^{\text {rd }}$ Annual Florida Ruminant Nutrition Symposium. Gainesville, FL (USA), pp. 44-52
Lesgards J.-F., Lehucher-Michel M.-P., Vidal N., Stocker P., 2005. Assessment of antioxidative activity of lipid- and water-soluble vitamins in human whole blood. Comparative analysis between a biological test and chemical methods. Int. J. Vit. Nutr. Res. 75, 11-18, https://doi.org/10.1024/0300-9831.75.1.11

McKiernan W.A., 2007. Muscle scoring beef cattle. NSW DPI Primefact No. 328

Nicholson J.W.G., McQueen R.E., Bush R.S., 1991. Response of growing cattle to supplementation with organically bound or inorganic sources of selenium or yeast cultures. Can. J. Anim. Sci. 71, 803-811, https://doi.org/10.4141/cjas91-095

NRC, 2000. Nutrient Requirements of Beef Cattle. $7^{\text {th }}$ revised Edition. Update 2000. National Academies Press. Washington, DC (USA), https://doi.org/10.17226/9791

OIE, 2012. Infectious bovine rhinotracheitis/infectious pustular vulvovaginitis. In: Manual of Diagnostic Tests and Vaccines for Terrestrial Animals. $7^{\text {th }}$ Edition. OIE World Organisation for Animal Health. Paris (France)

Oldfield J.E., 2002. Selenium World Atlas. Updated Edition. Selenium-Tellurium Development Association (STDA). Grimbergen (Belgium)

Panciera R.J., Confer A.W., 2010. Pathogenesis and pathology of bovine pneumonia. Vet. Clin. N. Am. - Food Anim. Pract. 26, 191-214, https://doi.org/10.1016/j.cvfa.2010.04.001

Prost M., 1992. Process for the determination by means of free radicals of the antioxidant properties of a living organism or a potentially aggressive agents. US Patent 5,135,850

Puls R., 1994. Mineral Levels in Animal Health: Diagnostic Data. $2^{\text {nd }}$ Edition. Sherpa International. Clearbrook (Canada)

Radostits O.M., Gay C.C., Hinchcliff K.W., Constable P.D., 2007. Veterinary Medicine. A Textbook of the Diseases of Cattle, Sheep, Pigs, Goats and Horses. $10^{\text {th }}$ Edition. Saunders Ltd. Philadelphia, PA (USA), pp. 923-946

Richards C.J., Blalock H.M., Jacques K.A., Loveday H.D., 2011. Efficacy of feeding selenium-enriched yeast to finishing beef cattle. Prof. Anim. Sci. 27, 1-8, https://doi.org/10.15232/S10807446(15)30437-X

Rossi R., Corino C., Pastorelli G., Durand P., Prost M., 2009. Assessment of antioxidant activity of natural extracts. Ital. J. Anim. Sci. 8, Suppl. 2, 655-657, https://doi.org/10.4081/ijas.2009. s2.655

Rossi R., Pastorelli G., Corino C., 2013. Application of KRL test to assess total antioxidant activity in pigs: Sensitivity to dietary antioxidants. Res. Vet. Sci. 94, 372-377, https://doi.org/10.1016/j. rvsc.2012.08.005

Sgoifo Rossi C.A., Compiani R., Baldi G., Bonfanti M., 2013. Determination and assessment of $B R D$ risk factors in newly received beef cattle (in Italian). Large Anim. Rev. 19, 65-72

Spears J.W., 2003. Trace mineral bioavailability in ruminants. J. Nutr. 133, 1506S-1509S

Stocker P., Lesgards J.-F., Vidal N., Chalier F., Prost M., 2003. ESR study of a biological assay on whole blood: antioxidant efficiency of various vitamins. Biochim. Biophys. Acta - Gen. Subj. 1621, 1-8, https://doi.org/10.1016/S0304-4165(03)00008-4

Teixeira A.G.V., Lima F.S., Bicalho M.L.S., Kussler A., Lima S.F., Felippe M.J., Bicalho R.C., 2014. Effect of an injectable trace mineral supplement containing selenium, copper, zinc, and manganese on immunity, health, and growth of dairy calves. J. Dairy Sci. 97, 4216-4226, https://doi.org/10.3168/jds.20137625

van de Wiel H.J., 2003. Determination of elements by ICP-AES and ICP-MS. National Institute of Public Health and the Environment (RIVM). Bilthoven (The Nederlands) 
Van Soest P.J., Robertson J.B., Lewis B.A., 1991. Method for dietary fiber, neutral detergent fiber and nonstarch polysaccharides in relation to animal nutrition. J. Dairy Sci. 74, 3583-3597, https://doi.org/10.3168/jds.S0022-0302(91)78551-2
Weiss W.P., 2005. Selenium sources for dairy cattle. In: Proceedings of the Tri-State Dairy Nutrition Conference. Fort Wayne, IN (USA), pp. 61-71 